\title{
PRESENTACIÓN \\ COLOQUIO REFORMA Y EDUCACIÓN PÚBLICA: UNA MIRADA DESDE LA UNIVERSIDAD DE CHILE
}

\section{Rector Ennio Vivaldi Véjar}

Apelando a lo mejor de la tradición que ha distinguido a la Universidad de Chile, hemos querido convocar a nuestra comunidad académica a reflexionar sobre la situación de la educación del país. Esta oportunidad coincide con la preocupación que distintos sectores de la sociedad han manifestado en los últimos años acerca de reconstruir las bases del sistema educacional chileno. Nuestra universidad ha asumido esta preocupación como suya porque pensamos que el país requiere que abordemos el debate sobre educación desde una mirada distinta a la que se ha intentado imponer en estos años, una mirada que en vez de fomentar la estrecha perspectiva individualista, sepa abarcar al país en su conjunto y a la educación como un proceso sistémico. Esa mirada exige preguntarnos qué tipo de educación y qué tipo de país queremos para el futuro.

En años recientes se ha desincentivado esta reflexión y se nos ha hecho demasiado hincapié en que cada cual tiene que preocuparse de sí mismo, porque si no, nadie más lo hará. Se nos ha hecho creer que cualquier opinión discrepante frente a este modo de ver el entorno es poco razonable. Este hecho nos parece un motivo suficiente en sí mismo para convocar a un debate en que todos los sectores de la comunidad universitaria puedan analizar con entera libertad un ámbito tan trascendente como el de la educación. En este debate sobre la educación chilena nos proponemos volver a manifestar nuestro pensamiento sobre los grandes temas nacionales. Queremos que la sociedad chilena vuelva a oír la voz de su universidad hablando acerca del país que soñamos para las generaciones del futuro.

Esa voluntad de construir un futuro diferente en educación fue expresada hace un par de años de manera muy elocuente por un movimiento estudiantil que tuvo un enorme eco en la sociedad. Al tenor de las movilizaciones del año 2011 fue quedando de manifiesto una verdad que no debe pasar inadvertida. Como todos sabemos, en Chile los determinantes ideológicos fundamentales, que marcan la vida de la sociedad y su quehacer cotidiano en aspectos tan relevantes como la educación y la salud, no han pasado por la discusión ni la aprobación ciudadana. Es precisamente la aceptación de esa situación como un dato de realidad inmutable 
lo que ha hecho creer a muchos que debatir estos temas no tiene sentido y, todavía peor, que no hay alternativa posible a un modelo de desarrollo que se impuso al margen del consentimiento democrático.

A la Universidad de Chile le interesa por sobre todo promover el diálogo porque éste es consustancial a su misión de examinar el rumbo del país y proponer caminos de solución a los problemas colectivos que la afectan. No queremos que se promueva tal o cual sistema. Lo que reclamamos, desde la función intelectual que cumplimos, es la necesidad de contar con espacios en los cuales podamos intercambiar ideas y hacer propuestas. Antes que el contenido y las conclusiones, nos importa el hecho mismo de volver a tener un debate, de volver a tener una discusión. En resumen, hoy día de lo que se trata es de pensar el país en su conjunto desde el énfasis que debe dársele a la educación pública.

El concepto de educación pública surgió primariamente en Europa en paralelo a dos fenómenos muy importantes: la construcción de los estados nacionales y la incorporación de sectores cada vez más numerosos de la población al sistema político a medida que avanzaban los procesos democratizadores. En esa historia la educación pública fue un pilar fundamental para el afianzamiento de la ciudadanía democrática y la construcción de la nación moderna. Allí donde la educación pública fue ampliando su radio de acción fue generándose más cohesión e integración social. Desde la creación de la Universidad de Chile en 1842, nuestro país siguió una trayectoria similar a la de los países europeos, llegando la educación pública a gozar de prestigio y reconocimiento, a pesar de sus limitaciones iniciales de cobertura. El fundado temor que compartimos como institución pública ligada al desarrollo de Chile es que la desaparición de este modelo educativo entre nosotros traiga un efecto negativo sobre estos dos conceptos fundamentales: nación y democracia, lo que implicaría que nos desdibujáramos como país y que perdamos los cimientos más importantes que están detrás de una organización social democrática.

El concepto de nación con el que todos nos comprometemos es el que otorga sello y marca a esta universidad. Este concepto nos hace sentirnos parte de un pueblo, de una historia cultural y política, de un conjunto de personas que son chilenos y chilenas y que deben ser respetados como tales. Parte esencial de ese respeto se funda en el ordenamiento democrático que les confiere a esos ciudadanos el derecho al acceso a la educación para sus hijos, el derecho a la salud y derecho a una jubilación adecuada, entre muchos otros.

Desde ese punto de vista, entonces, el concepto de nación enfatiza la pertenencia a un mismo sentido espiritual, histórico, cultural y social, y eso, sin duda, es lo que se ha visto amenazado con el debilitamiento de la educación pública. Algunos ejemplos de las amenazas que nos afectan y nos preocupan permiten ver con claridad que la idea de reforma del sistema educacional está respaldada por el afán 
de revertir los efectos nocivos de situaciones que, por desgracia, se han hecho parte de la vida cotidiana de las familias chilenas. Cuando vemos fenómenos como el copago y la selección cabe preguntarse hasta qué punto el objetivo principal de esos instrumentos sea que cada chileno se sienta obligado, para beneficiar a sus hijos, a pagar por lo que simplemente es una forma de discriminación o segregación respecto a quienes no pueden pagar.

En efecto, los estudios muestran claramente que el copago no ofrece una mejor educación propiamente tal y que son factores ajenos a la escuela los que explican los resultados de las pruebas que se aplican para medir el desempeño de los estudiantes. Si las familias que pagan más por la educación de sus hijos obtienen mejores resultados académicos es por factores que son independientes de la calidad de la educación, es decir, por factores socioculturales inherentes a las prerrogativas con que puede contar un núcleo familiar con mejor situación económica. De esto emanan dos preguntas centrales: En primer lugar, ¿qué es lo que se paga cuando se paga más? Y en segundo lugar, ¿por qué habría uno de pagar un adicional si la oferta basal de la nación fuera de una calidad adecuada?

Resulta inevitable preguntarse si acaso el país, siguiendo con la trayectoria que venía desarrollando desde los orígenes de nuestra educación pública, hubiera mantenido el rumbo con el que se fueron sucesivamente haciendo reformas para ampliar la cobertura y mejorar la calidad, seguramente no estaríamos lamentando el estado en que hoy se encuentra, ni los efectos nocivos que genera este sistema que desde hace ya algunas décadas cambió drásticamente el sentido de lo que es educar. Por eso es que sostenemos que, desde una perspectiva histórica, lo que está en juego en la reforma a la educación que actualmente el país debate es terminar con un negocio que consiste en vender segregación. Lo que verdaderamente le está diciendo a la familia el sistema actual es "mire, si usted nos paga tanto, nosotros garantizamos que sus hijos no se van a mezclar con niños que no tengan el poder adquisitivo que les permita pagar este colegio". Ese es un concepto que como chilenos, como nación, como pueblo, tiene que preocuparnos enormemente.

Lo que está en discusión es si queremos preservar la riqueza y la diversidad que el pluralismo y la no segregación entregan en la educación superior, o si queremos en los niveles prebásico, básico y medio profundizar la brecha que separa y divide a la población chilena en compartimentos estancos ordenados jerárquicamente por niveles de ingreso. En la Universidad de Chile constatamos cómo muchos estudiantes se impactan al conocer la realidad cotidiana y las condiciones de vida de personas con las que ellos nunca pudieron compartir en los colegios privados donde se educaron. Me parece que eso es tremendamente relevante desde el punto de vista de nuestra nación y constituye una riqueza que debemos saber apreciar y preservar. 
La educación pública es una educación que lo compromete a uno con el país que lo formó. Eso se demuestra en los afectos y en la emoción de todos los que nos formamos en un sistema de educación gratuita. Fue el país el que nos dio el privilegio y la opción de educarnos y de estudiar una profesión, y es a ese país al que nos debemos. Hoy discutimos muy frecuentemente por qué no hay vocación de servicio público Esto no deja de ser un dato relevante e interesante. Nosotros, con un tremendo esfuerzo, hemos seguido formando, por ejemplo, excelentes profesores para la enseñanza media, pero cuando ellos terminan sus estudios las condiciones de trabajo en establecimientos públicos resultan muy poco incentivadoras.

Las políticas orientadas a reforzar lo público a todo nivel deben pensarse teniendo en cuenta que es fundamental para nuestra convivencia volver a suscitar en nuestra juventud la vocación y el compromiso con el servicio público. Amar y sentir al país como propio es lo que hizo en el pasado posible que grandes profesionales fueran capaces de compatibilizar su desarrollo individual con la noble idea de servir a Chile para responder a esa deuda emocional con la educación pública que los formó. Es muy esclarecedor escuchar cómo la defensa de lo público ha ido ganando adeptos en el último tiempo, porque, hay que decirlo, a ratos en el debate sobre educación las palabras, empezando por la palabra "público", se suelen tergiversar hasta hacerlas perder todo significado.

Curiosamente, a la hora de discutir sobre financiamiento del Estado todas las universidades quieren ser públicas. Sin embargo, son sólo las universidades del Estado las que enmarcan su funcionamiento dentro de las normas que les fija el derecho público. Se pueden pensar muchos mecanismos que le permitan al Estado transferir fondos a todas las universidades, ya sea a través del financiamiento a la investigación o apoyando a los estudiantes en situación vulnerable, independiente de la condición de públicas o no de esas universidades, pero lo que hoy se plantea es una discusión donde, a fuerza de querer homologar realidades que no son comparables, se usan conceptos impropios para dar cuenta de la naturaleza de las instituciones de educación superior.

Se habla, por ejemplo, de si es correcto que las universidades del Estado reciban un trato "preferencial". No hay país en el mundo donde el aporte estatal a las universidades estatales sea considerado un acto discriminatorio para con el resto de las universidades. Es inconsistente utilizar el concepto de "preferencia" para aludir al financiamiento de las universidades estatales, ya que éstas son instituciones del Estado y, por lo tanto, son entidades que operan dentro de la lógica que el Estado, como representante del interés común, les encarga para cumplir con su misión de servicio público. Por otra parte, el hecho inédito de que se cuestione el financiamiento a las universidades estatales no se condice con el espíritu que siempre ha primado en la comunidad académica, caracterizado por la colaboración, 
la interacción constructiva y los proyectos conjuntos. Nos parece que lo que realmente está en juego en este debate es si, después de varias décadas, por fin Chile se puede plantear si quiere o no volver a tener una educación pública, incluyendo universidades públicas, o si seguiremos viviendo este insólito mundo local que las prohíbe.

El año 1981 se instauraron políticas al margen de la deliberación ciudadana. Algunas normativas recuerdan pasajes de las novelas decimonónicas de comienzos de la Revolución Industrial, como el orfelinato de Oliver Twist. Si uno se plantea un debate "de cara al siglo XXI" lo más importante es saber dejar atrás el siglo de los extremos, en que las esperanzas del mundo se vieron frustradas por dos guerras mundiales, totalitarismos, dictaduras y terror. Para encontrar nuestro propio camino como nación y discutir con alturas sobre el futuro de nuestra educación y de nuestra sociedad, tenemos que aprender a reencontrarnos con valores universales, como son la responsabilidad que el país tiene para con su juventud, expresada en la garantía de una educación pública en todos sus niveles.

No es teniendo un debate ideológico disfrazado de uno económico que vamos a lograr avanzar en la definición de los asuntos públicos más importantes del país. Bajo el argumento económico de la igualdad de trato entre universidades públicas y privadas simplemente se termina perseverando en un sistema que a través del autofinanciamiento incentiva lógicas que, tanto en la formación de los estudiantes como en el trabajo de la universidad, nada tienen que ver con la auténtica impronta de servicio al país, de reconocerse como parte de un pueblo, de una nación, de una cultura, que es lo propio de la función de las universidades estatales. Lo que está en juego en el debate sobre educación en general y sobre financiamiento de la educación superior en particular es demasiado importante como para hacer del financiamiento el debate de fondo que tenemos que sostener como sociedad. La tarea que tenemos como universidad pública hoy conlleva una gran responsabilidad, pero también una oportunidad particularmente apasionante de proyectar nuestro quehacer hacia nuevos horizontes, con nuevas formas de mirar y entender nuestra misión de servir a Chile. 